\title{
Issues of rational distribution of water resources under deficit conditions
}

\author{
Maksadhon Yakubov ${ }^{1}$, Yusufbek Gafurov ${ }^{1}$, and Lyudmila Varlamova $^{2}$ \\ ${ }^{1}$ Tashkent University of information technologies, Tashkent, Uzbekistan \\ ${ }^{2}$ National University of Uzbekistan named after Mirzo Ulugbek, Tashkent, Uzbekistan
}

\begin{abstract}
Water is one expensive resource that can run out. The article discusses the issues of determining property rights, which is one of the necessary conditions for the effective functioning of the market mechanism. In Uzbekistan, the source of clean water is groundwater, which is less prone to pollution than surface water. The paper considers two systems of water consumption rights: riparian and appropriative. The features of these systems are presented. In addition, the uneven distribution of water resources across regions requires large investments in transportation through the construction of branch canals and the laying of extended water supply networks. It should be noted that the benefits of the constructed canals will vary significantly for water users depending on their location. Due to water losses when passing through the diversion canal, agents located at the beginning of the diversion canal find themselves in an advantageous position compared to other water users. At the same time, investments in the maintenance of the water distribution system, made at the beginning of the branch canal, bring benefits to all water users located downstream. One of the most well-known approaches to constructing an indicator of water scarcity is the Falkenmark water stress index.
\end{abstract}

\section{Introduction}

Currently, the country pays due attention to the efficient use of water resources; the President of the Republic of Uzbekistan has approved a strategy for water resources management. In many regions of the country, the shortage of clean, fresh water has turned from a hypothetical possibility into today's problem. The peculiarity of water resources lies in the variability of their quality due to pollution, on the one hand, and the presence of natural absorption, on the other hand. In many countries, water resources are owned by the state. Perhaps one of the reasons for such a policy is the peculiarities of water resources. Unlike most other resources, water is characterized by a continuous change in both quantitative and qualitative composition. This inevitably creates difficulties in the proper determination of property rights, which is one of the necessary conditions for the effective functioning of the market mechanism. It should be noted that different sources of water resources vary significantly in the degree of variability in the quantity and quality of water flow. In particular, groundwater is not as susceptible to seasonal fluctuations as surface 
water runoff and has more consistent quality characteristics because it is less prone to pollution than surface water [1-3].

The most widespread are two systems of rights: riparian and appropriative. The Riparian system assumes that the land owner on which the water body is located (lake, river, etc.) can use this object on an equal basis with other agents.

However, upstream users have the overriding right to "wise" water use over those who live downstream, as the latter later receive the right to use. In this system, the agent does not lose the right to use water resources in the future if not uses them at present. An alternative is the appropriative system of rights, in which the right to use a water resource belongs to the one who discovered it or started using it first. In contrast to the Riparian doctrine, with this system of rights, the user receives a designated amount of water at his exclusive disposal. However, if the right owner does not use the resource in full or does not use the resource for some time, he may be deprived of the right to use it in the future [4].

Comparing the two doctrines, it can be noted that the Riparian system is appropriate when using water resources for bathing, fishing, shipping, and in the electric power industry, i.e., where the use of water does not reduce the number of water resources available to other agents, or, in other words, water acts as a public good.

The appropriative doctrine, on the contrary, is reasonable in those cases where the use of water is associated with water intake and entails some kind of irrevocable water consumption, that is, in the case where water acts as a private good. This option takes place when using water in industry, agriculture and housing and communal services.

Seasonal dependence of precipitation and evaporation rate leads to significant fluctuations in the supply of water resources, mainly reflected in surface water runoff. In addition to seasonal fluctuations in supply, which are highly predictable, river flows and associated water levels in underground deposits vary significantly from year to year, sometimes causing sharp deviations from the average long-term values. These deviations can cause flooding in some cases and drought in others. Suppose the system of rights presupposes a certain priority of access to water resources. In that case, drought does not affect the consumption volumes of high-priority users. Still, at the same time, water consumption for low-priority users is significantly reduced, i.e., we are dealing with ineffective risk distribution. This problem can be solved if some mechanisms of water trade are in place. Another approach to this issue is to establish the use rights in terms of relative (as a fraction of the flow of a given period) rather than absolute (volume of water withdrawn) values. In this case, a change in drainage is automatically accompanied by a proportional change in water intake, distributing risks among all water users.

The problem of changing the quality of water resources is also important to surface water management. It should be borne in mind here that upstream agents affect the amount of water available to downstream agents and their wastewater discharges determine the downstream water quality.

On the one hand, water is an example of a stored resource, making it possible to level the variability of water flow. However, on the other hand, the storage of water requires the creation of special reservoirs (artificial reservoirs), which is associated with high investment costs. At the same time, all water users in the region benefit from the use of these reservoirs, i.e., such projects are a local public good. In addition, the uneven distribution of water resources across regions requires large investments in transportation through the construction of branch canals and the laying of extended water supply networks. It should be noted that the benefits of the constructed canals will vary significantly for water users depending on their location. Due to water losses when passing through the diversion canal, agents located at the beginning of the diversion canal find themselves in an advantageous position compared to other water users. At the same time, 
investments in the maintenance of the water distribution system, made at the beginning of the branch canal, bring benefits to all water users located downstream.

In the absence of a centralized approach to establishing and maintaining a water distribution system, which is an example of a public good, investment in the creation of this system may be lower than the optimal value. As a result, the system will cover too few users compared to the optimal one.

The problem with meeting demand arises only if the physical supply of water is insufficient to meet all needs at a certain point in time. The difference between water resources and many other goods and services is that natural replenishment of resources occurs due to precipitation [5]. Moreover, these resources are accumulated (for example, groundwater), and therefore a redistribution of consumption over time is possible. In this regard, difficulties in providing all consumers with water arise at certain points in time due to a significant decrease in water supply caused by drought, i.e., such a shortage is, as a rule, a temporary phenomenon associated with the uncertainty of river flow. Moreover, this problem can be solved through sound water management policies [5-7]. Hydrological and climatic observations and studies make it possible to predict river flow fluctuations and smooth out the corresponding water supply through the construction of dams and reservoirs. In addition, it is possible to use the natural reserve of groundwater during dry periods with a reasonable combination of various natural sources of water supply $[7,8]$.

Both opportunities and needs in the economy change with time, not only due to population growth or exhaustion of resources but also due to technology development. Accordingly, investments in the capacity of the corresponding technologies directly depend on the economic mechanisms used for the distribution of water resources [6-9].

One of the most well-known approaches to constructing an indicator of water scarcity is the Falkenmark water stress index $[10,11]$. The idea of this index is that in the world, the volume of fresh water available for consumption does not increase over time, but the population grows, which, all other things being equal, entails a decrease in water consumption per capita. Thus, we can determine the available volume of water consumption per capita for each region and correlate the obtained values with some critical values. It is customary to distinguish two threshold values, which are indicators of water stress. If the volume of replenished water resources per person turns out to be less than $1700 \mathrm{~m} 3$ / year, then we speak of the presence of water stress. If this indicator turns out to be below $1000 \mathrm{~m} 3$ per capita on an annualized basis, then it is said that there is a shortage of water resources. Finally, when this indicator falls below the level of $500 \mathrm{~m} 3$, this situation is called an absolute deficit. When calculating the required level of water consumption, both the personal needs of individuals, which are about $35 \mathrm{~m} 3$ / year and the needs of agriculture and industry, which are the main water consumers, were taken into account $[12,13]$. Table 1 shows data on the change in the Falkenmark index for several countries of the world in the period from 1992-2007. According to this index, an absolute water shortage is observed in the UAE, Israel and the Republic of Moldova, and water shortages also occur in Hungary, Uzbekistan, the Netherlands and Azerbaijan. 
Table 1. Water availability dynamics

\begin{tabular}{|c|c|c|c|c|c|c|}
\hline \multirow{2}{*}{ Country } & \multicolumn{5}{|c|}{ Internal renewable water resources, M 3 per person per year } \\
\cline { 2 - 6 } & 1992 & 1997 & 2002 & 2007 & 2015 & 2018 \\
\hline Arabian Emirates & 72.4 & 54.9 & 41.8 & 34.4 & 31.1 & 34.4 \\
Israel & 155.3 & 132 & 118.4 & 108.2 & 101.3 & 108.2 \\
The Republic of & 228.4 & 234.4 & 252.5 & 272.7 & 277.3 & 272.7 \\
Moldova & 580.2 & 582.8 & 590.7 & 598.1 & 601.5 & 598.1 \\
Hungary & 759.9 & 688.7 & 642.9 & 607.4 & 592.2 & 607.4 \\
Uzbekistan & 726 & 703.3 & 683.9 & 668.3 & 643.6 & 668.3 \\
Netherlands & 1089 & 1022 & 984.6 & 940.1 & 924.4 & 940.1 \\
Azerbaijan & 1425 & 1294 & 1187 & 1099 & 1085 & 1099 \\
India & 1161 & 1138 & 1117 & 1102 & 1007 & 1102 \\
Denmark & 1030 & 1056 & 1106 & 1147 & 1166 & 1147 \\
Ukraine & 1331 & 1306 & 1301 & 1299 & 1281 & 1299 \\
Germany & 1397 & 1389 & 1398 & 1406 & 1418 & 1406 \\
Poland & 1988 & 2188 & 2241 & 2233 & 2221 & 2233 \\
Armenia & 2510 & 2475 & 2432 & 2372 & 2366 & 2372 \\
Great Britain & 2848 & 2808 & 2695 & 2524 & 2647 & 2524 \\
Spain & 2427 & 2562 & 2661 & 2748 & 2674 & 2748 \\
Bulgaria & 3113 & 3056 & 2983 & 2892 & 2831 & 2892 \\
France & 3196 & 3196 & 3169 & 3077 & 3066 & 3077 \\
Italy & 3908 & 3584 & 3319 & 3109 & 3092 & 3109 \\
Turkey & 4719 & 4307 & 4008 & 3805 & 3728 & 3805 \\
Mexico & 3613 & 3647 & 3736 & 3826 & 3799 & 3826 \\
Belarus & 4213 & 4350 & 4488 & 4636 & 4742 & 4636 \\
Lithuania & 4590 & 4872 & 5053 & 4895 & 4933 & 4895 \\
Kazakhstan & 5602 & 5364 & 5273 & 5220 & 5223 & 5220 \\
Greece & 5898 & 5686 & 5549 & 5377 & 5145 & 5377 \\
Switzerland & 7071 & 6900 & 6804 & 6621 & 6574 & 6621 \\
Austria & 6406 & 6875 & 7163 & 7378 & 7403 & 7378 \\
Latvia & 10797 & 10153 & 9585 & 9129 & 8955 & 9129 \\
USA & 10931 & 10355 & 9659 & 9156 & 8929 & 9156 \\
Kyrgyzstan & 8324 & 9066 & 9366 & 9464 & 9687 & 9464 \\
Estonia & 10874 & 11805 & 12558 & 13339 & 13574 & 13339 \\
Georgia & 19703 & 19322 & 19162 & 18670 & 19162 & 18670 \\
Sweden & 21251 & 20821 & 20581 & 20254 & 20064 & 20254 \\
Finland & 28073 & 26563 & 25034 & 23593 & 21444 & 23593 \\
Australia & 35071 & 32511 & 30247 & 28498 & 26195 & 28498 \\
Brazil & 29006 & 29141 & 29675 & 30386 & 31753 & 30386 \\
Russian Federation & & & & & & \\
\hline & & & & & &
\end{tabular}

The Falkenmark Index, for example, does not take into account the development of technologies that change our understanding of the water intensity of production when introducing water-saving technologies. In addition, with an increasing water shortage, a change in the structure of production itself is possible: in water-deficient regions, a transition to less water-intensive production activities is possible, accompanied by the import of water-intensive goods [10-13].

The need to conduct a comparative cross-country analysis of water availability, taking into account economic and environmental characteristics, led to the construction of a specific poverty index (water poverty index). This index is intended to reflect five aspects of the region's water supply: resource reserve, access to water resources.

Dynamics of water supply for several countries of the world (1992-2018), the socioeconomic situation of the region, water consumption by economic sector, environmental characteristics of water use. 
This index helps in making decisions about assisting countries in need to improve the provision of water supply and sanitation services. Still, it does not solve the problem of assessing the scarcity of water resources. Note that aggregated information does not always allow an adequate assessment of the degree of scarcity of water resources since it does not consider the unevenness both in the distribution of the resources themselves and in the distribution of consumers of these resources in the region.

Let's consider various options for water distribution in conditions of shortage. Note that the natural market reaction to the emergence of a shortage increases the price of the product. Still, the authorities rarely resort to raising tariffs to eliminate water shortages.

Temporary tariff increases are the simplest control measure but are not the most common ways to manage deficits [14].

Price regulation is the best solution to the problem, as the increase in tariffs gives the right signal to consumers and stimulates the reduction of water consumption. In this case, the problem of information asymmetry does not arise since each agent chooses the amount of water consumption reduction by himself, which makes it possible to effectively distribute the costs associated with the reduction in consumption between water users. A sharp increase in tariffs can negatively affect the situation of poor households, and therefore such a policy requires appropriate social support measures. In addition, price regulation is effective only if consumers pay for actual water consumption. However, in many, due to the lack of water measuring devices among consumers, payment is made according to the standard. In these conditions, the increase in tariffs will only reduce the welfare of consumers but will not stimulate water conservation.

So. in the presence of a temporary imbalance between the demand and supply of water, the authorities can resort to a temporary increase in tariffs or use rationing in the form of restrictions on the volume of water consumption.

Another form of rationing is the introduction of a universal. i.e., the same for all consumers, quantitative restrictions on the volume of water consumption. This measure is easy to implement, but it leads to inefficient distribution of a limited resource between users since it ignores the problem of heterogeneity of water users: for some. a reduction in water consumption is associated with higher costs than for others. A variation of the above method is a proportional rationing scheme, in which, in the event of a drought, all consumers are faced with a restriction on water consumption, which is a certain fixed share of their usual water consumption for a given period. On the one hand, this rationing option, to some extent, takes into account the differences in needs but, on the other hand, this option also has its drawbacks. First, the implementation of this principle is not always possible since for some agents (households that have moved to a given region or new firms), data on previous water consumption are not available. On the other hand, this rationing option does not create incentives for water conservation since a high level of water consumption allows a higher quota to be obtained during a drought.

Note that the use of quantitative restrictions in rationing is associated with certain costs associated with monitoring water consumption. In addition, it requires the introduction of a system of warnings, fines and, in extreme cases, the interruption of water supplies, encouraging users to adhere to the imposed restrictions. Experience shows that the role of the enforcement control system in reducing water consumption is very significant.

It should be noted that the parameters of the elasticity of water demand used in assessing the gain can, in fact, vary depending on the season, income and other characteristics of consumers, as well as on characteristics of the region. This means that estimates of rationing losses obtained for one situation cannot be automatically extended to others. In particular. water demand is less price sensitive in summer. As a result, estimates of losses in consumer surplus from tariff increases obtained for different seasons differ significantly: the largest losses during drought corresponded to the hottest period from July 
to October. The gains for agents from replacing quantitative restrictions with tariff regulation vary significantly for different groups of the population: for rich households with large holdings, this gain turned out to be almost 10 times higher than for rich households with smallholdings.

\section{Methods}

It is important to take into account the specifics of the region. For example, in the case of a densely populated city, measures related to limiting the use of water for irrigation are unlikely to lead to a significant limitation of water use. Price regulation is the preferred way of allocating water in conditions of scarcity [3.10.11.15]. Different rationing schemes affect public welfare in the framework of the partial equilibrium model presented below.

So. let each agent $k(k=1 \ldots . M)$ choose the volume of water consumption $x_{t}^{k}$, maximizing its surplus for a given linear water tariff with rate $p$ :

$$
\max _{x_{k} \geq 0} \int_{0}^{T}\left(v_{k}\left(x_{k}(t)\right)-p x_{k}(t)\right) d t
$$

where $T$ is a period (for example. a month), and the instantaneous utility from water consumption $v_{k}(\cdot)$ is assumed to be an increasing and strictly concave function. For convenience, we will assume that all agents are ranked following their estimates of water consumption in ascending order i.e., $v_{1}<v_{2}<\ldots<v_{M}$. Further, for simplicity, we take the period length equal to one.

Solving the problem, we find that in the absence of restrictions, consumers prefer a smoothed consumption trajectory: $x_{k}(t)=x_{k}$.

$$
v_{k}\left(x_{k}\right)=p
$$

where $x_{k}$ is a solution to the equation (2)

Substituting the found values of water consumption into the objective function of problem (1) and summing over all consumers, we find the total surplus of consumers in the economy [16].

$$
C S(p)=\sum_{k=1}^{M}\left(v_{k}\left(x_{k}\right)-\left(p x_{k}\right)\right)
$$

Let us sum up the solutions to problems $x_{k}$ for all agents and find the total water consumption in the absence of restrictions, which we denote by $X$. Consider the situation of water resources shortage, assuming that the actual supply is a certain fraction $\beta(0<\beta<1)$ of $X$. To eliminate the shortage by of price increases, it is necessary to find the tariff $p_{\beta}$ at which the aggregate demand would be equal to $\beta X$. i.e. $p_{\beta}$ is a solution to the equation [17]

$$
\sum_{k=1}^{M} v+k^{-1}(p \beta)=\beta X
$$

Then, substituting the found tariff $p_{\beta}$ and the demand value $x_{k} p \beta$, found from Equation (2) into the objective function, we obtain the agent's consumer surplus $k$ : $C S_{k} p_{\beta}$. Note that the tariff increase allowed water supply companies to receive additional income [17-19]. This means that if, for example, in the initial situation, the tariffs were set in such a way as 
to guarantee the water supply companies coverage of costs, then now the companies have made a profit, and this profit can be used to compensate consumers. Then the surplus of consumers, taking into account these compensations, will be

$$
C S^{\mathrm{comp}}(\beta)=\Sigma_{\kappa} C S_{k}\left(p_{\beta}\right)+\left(p_{\beta}-p\right) \beta X .
$$

If, for some reason, it is impossible to change tariffs, then some rationing option will be used when distributing a scarce resource. The simplest way is to introduce universal quotas, which determine the maximum permissible level of water consumption for each user. Note that the quota for some agents may exceed the desired level of water consumption. For such agents, the actual level of water consumption will be below the quota. Since the desired level of water consumption is a solution to the equation $v_{k}\left(x_{k}\right)=p$, then due to the decrease in the marginal utility of water consumption and the orderliness of consumer estimates, we have $\mathrm{x}_{1}<x_{2}<\ldots<x_{M}$.

This means that the quota may not be exhausted only by the first consumers. So, let the introduced quota $x^{*}$ turn out to be higher than the water consumption level [20.21] of the first $\mathrm{n}$ agents and is constraining for the rest, then the total water consumption level will be $\sum_{k=1}^{n} x_{k}+x *(M-n)$

For each deficit level $\beta$, we find a quota $x_{\beta}$ and the number of consumers $n_{\beta}$ for which the quota is not effective, such that

$$
\sum_{k=1}^{n_{\beta}} x_{k}+x_{\beta} *(M-n \beta)=\beta X .
$$

As a result of introducing such quotas, the welfare of the first $n_{\beta}$ consumers will not change, and the rest will decrease due to a decrease in water consumption [20]. As a result, the total consumer surplus with universal rationing will be equal to

$$
\operatorname{CS}^{\text {univ }}(\beta)=\sum_{k=1}^{n_{\beta}} C S_{k}(p)+\sum_{k=n_{\beta}}^{M} C S_{k}(x * \beta) .
$$

where $C S_{k}(x * \beta)=v_{k}(x * \beta)-p x * \beta$.

Proportional rationing can be considered as an alternative to universal quotas [21-23]. In this case, the quota of each agent will be a fixed share of his previous level of water consumption $x_{k}^{\text {prop }}=\beta x_{k}$. In this case, quotas will be effective for all individuals, and the surplus of consumers will be

$$
\operatorname{CS}^{p r o p}(\beta)=\sum_{k=1}^{n_{\beta}}\left(v_{k}\left(\beta x_{k}\right)-p \beta x_{k}\right) .
$$

Finally, another way of distributing a resource in conditions of shortage is associated with limiting the time of its use; that is, the resource is supplied intermittently during the period under consideration. Let's start our analysis of this regulation method with the case when consumers do not try to accumulate water during the period of its supply for the purpose of subsequent use. Let the period of water supply be a fraction $\beta$ of the considered time interval. In this case, during this period, water consumption will be the same as in the absence of a deficit, and at other times, water consumption will be zero. Thus, with the actual proposal $\beta X$, we obtain the following relation for determining the water supply period: 
$(1-\tau) \cdot 0+\tau X=\beta X$. whence $\tau=\beta$. The resulting consumer surplus will be

$$
C S^{\text {interrupt }}(\beta)=\beta \sum_{k=1}^{M}\left(v_{k}\left(x_{k}\right)-p x_{k}\right)+\left(1-\beta \sum_{k=1}^{M} v_{k}(0)\right. \text {. }
$$

Let us turn to a modification of the mechanism proposed above, where consumers are trying to smooth out surges in water consumption caused by interruptions in water supply due to the installation of water storage equipment. We will assume that the size of this equipment is the same for all agents and is a fixed fraction $\delta$ of the average volume of water consumption in the absence of a deficit. As a result, if water is supplied only for a fraction of the time $\tau$, then due to water storage equipment, each agent manages to maintain water consumption at the level $x(\delta)=\tau \delta X /(1-\tau) M$ in the remaining interval. Then the service period leading to the total water consumption equal to the water supply $\beta X$ can be found by solving the equation $\tau \delta X+\tau X=\beta X$. whence $\tau=\beta /(1+\delta)$. Denoting through $I$ the costs associated with the purchase and installation of water storage equipment, we obtain the following expression for the surplus of consumers

$$
C S^{\text {inter_inv }}(\beta . \delta)=\beta /(1+\delta) \sum_{k=1}^{M}\left(v_{k}\left(x_{k}\right)-p x_{k}\right)+\left(1-\frac{\beta}{1+\delta \sum_{k=1}^{M} v_{k}(x(\delta))}-p x(\delta)\right)-I .
$$

We considered the case with the same investments in water storage equipment, but agents with different water consumption estimates can choose different amounts of investment. Consider, for example, a situation in which the capacity of water storage equipment is proportional to the individual volume of water consumption. In this case, agents will consume different amounts of water during the period of its shutdown: $x_{k}(\delta)=$ $\tau \delta x_{k} /(1-\tau)$. It is easy to check that the value of $\tau$ will not change in this case, and in the expression for the surplus of consumers, only the component related to water consumption during a break in water supply will change, since $x(\delta)$ will be replaced by $x_{k}(\delta)$. To compare the above options for rationing with tariff regulation, let us consider two examples that differ in the specification of demand functions (2). For simplicity, in both examples, we will consider only two groups of consumers. In the first case, we consider groups with the same price elasticity of demand, and in the second, with different elasticities. In both cases, the parameters are selected in such a way that both the elasticity of aggregate demand and the values of demand at the starting point would be the same.

\section{Results and Discussion}

Following a review of empirical studies of the elasticity of water demand [24], the value of the elasticity of demand at the starting point is set equal to -0.4. At the same time, the elasticity (taken in modulus) grows with a price increase, which is also quite consistent with the empirical results. The parameters of the considered examples are reflected in table 2. 
Table 2. Model parameters and initial equilibrium

\begin{tabular}{|c|c|}
\hline Example 1 & Example 2 \\
\hline$x_{k}=\theta_{k}(1-b p)$ & $x_{k}=a_{k}-b p$ \\
$\theta_{1}=1$ & $a_{1}=32$ \\
$\theta_{2}=2$ & $a 2=52$ \\
$a=28 . b=4 / 15$ & $b=0.4$ \\
\hline \multicolumn{2}{|c|}{ Initial rate: $p=300$ sum. $/ \mathrm{m}^{3}$} \\
Initial water consumption of the agent per \\
month: $x_{1}=20 \mathrm{~m}^{3} . x_{2}=40 \mathrm{~m}^{3}$ \\
\hline
\end{tabular}

Next, we will consider several possible levels of water scarcity: from an insignificant deficit of $5 \%$ of the planned water consumption to an acute deficit of $40 \%$ of the demand. The deficit level is calculated as the percentage deviation of the supply value from the demand value calculated at the existing tariffs. i.e., this value is equal to $(1-\beta) \cdot 100 \%$. For each of the demand specifications, we will find tariffs that allow us to eliminate this deficit and calculate the corresponding values of consumers' surplus, taking into account compensation, substituting the found tariffs into expression (3). Next, we calculate the loss in the consumer surplus (taking into account compensations) as a percentage of the initial value. The results obtained are presented in table 3 . Note that with a small deficit, there is no significant difference either in terms of tariff increases or in terms of losses for the two demand specifications considered. However, when the deficit is over $20 \%$, the difference becomes significant.

Table 3. Losses in consumer surplus (as a percentage of the initial value) with different methods of deficit regulation

\begin{tabular}{|c|c|c|c|c|c|c|c|}
\hline \multirow[t]{2}{*}{$\begin{array}{c}\text { Water } \\
\text { deficit.\% }\end{array}$} & \multirow{2}{*}{$\begin{array}{c}\text { Deficit } \\
\text { elimination } \\
\text { tariff sum/ } \\
\mathrm{m}^{3}\end{array}$} & \multirow{2}{*}{$\begin{array}{c}\text { Losses } \\
\text { when } \\
\text { increasing } \\
\text { tariff. } \\
\%\end{array}$} & \multirow{2}{*}{$\begin{array}{c}\text { Losses } \\
\text { under } \\
\text { universal } \\
\text { quotas.\% }\end{array}$} & \multirow{2}{*}{$\begin{array}{c}\text { Losses at } \\
\text { proportional } \\
\text { quotas. } \%\end{array}$} & \multicolumn{3}{|c|}{$\begin{array}{l}\text { Losses during interruptions in } \\
\text { water supply.\% }\end{array}$} \\
\hline & & & & & $\begin{array}{c}\text { Variant } \\
\text { (a) }\end{array}$ & $\begin{array}{c}\text { Variant } \\
\text { (b) }\end{array}$ & $\begin{array}{l}\text { Variant } \\
\text { (c) }\end{array}$ \\
\hline \multicolumn{8}{|c|}{ Demand case with the same price elasticity (example 1) } \\
\hline 5 & 33.8 & 0.3 & 0.4 & 0.3 & 5.0 & 2.5 & 1.8 \\
\hline 10 & 37.5 & 1.0 & 1.5 & 1.0 & 10.3 & 6.3 & 5.8 \\
\hline 15 & 41.3 & 2.3 & 3.4 & 2.3 & 16.3 & 11.4 & 11.1 \\
\hline 20 & 45.0 & 4.0 & 6.0 & 4.0 & 22.7 & 17.4 & 17.1 \\
\hline 25 & 48.8 & 6.3 & 9.4 & 6.3 & 29.5 & 23.9 & 23.7 \\
\hline 30 & 52.5 & 9.0 & 13.5 & 9.0 & 36.6 & 30.9 & 30.7 \\
\hline 35 & 56.3 & 12.3 & 17.5 & 12.3 & 43.8 & 38.0 & 37.9 \\
\hline 40 & 60.0 & 16.0 & 20.5 & 16.0 & 50.5 & 44.8 & 44.8 \\
\hline \multicolumn{8}{|c|}{ Demand case with different elasticities (example 2) } \\
\hline 5 & 33.8 & 0.2 & 0.5 & 0.3 & 5.0 & 3.0 & 1.8 \\
\hline 10 & 37.5 & 0.9 & 1.8 & 1.0 & 10.4 & 7.1 & 5.9 \\
\hline 15 & 41.3 & 2.0 & 4.1 & 2.3 & 16.5 & 12.6 & 11.3 \\
\hline 20 & 45.0 & 3.6 & 7.2 & 4.0 & 23.2 & 18.9 & 17.6 \\
\hline 25 & 48.8 & 5.6 & 11.3 & 6.3 & 30.4 & 25.8 & 24.6 \\
\hline 30 & 52.5 & 8.1 & 16.2 & 9.0 & 37.9 & 33.1 & 31.9 \\
\hline 35 & 56.3 & 11.0 & 21.0 & 12.3 & 45.5 & 40.6 & 39.5 \\
\hline 40 & 60.0 & 14.4 & 24.4 & 16.0 & 52.6 & 47.7 & 46.7 \\
\hline
\end{tabular}


As an alternative to increasing tariffs, the following regulation methods were considered: universal quota policy, proportional rationing and water supply restrictions. In the latter case. three options were considered: (a) the absence of water-saving equipment. (b) the availability of the same water-saving equipment for all consumers, and (c) the availability of equipment whose capacity is proportional to the individual volumes of water consumption before the restriction was imposed [24]. For each of the considered cases, the corresponding values of consumers' surplus were found according to formulas (4) - (. 6), Table 3. Losses in consumer surplus are given as a percentage of its initial value.

It should be noted that when analyzing the policy of temporarily limiting water supply, the capacity of water storage equipment was taken equal to $10 \%$ of the average volume of water consumption in case (b) and the individual volume in case (c). In addition. investment costs were not taken into account when calculating consumer surplus. As a result, tactical losses under these schemes will be higher than the values presented in Table 3. Comparing the results obtained, it should be noted that tariff regulation, taking into account compensation for any demand specification, gives the lowest level of losses. However, in the case of demand with the same elasticity, proportional rationing is just as effective. This effect is explained by the fact that the same price elasticity characterizes the demand functions of all consumers in example 1, while in example 2 the elasticities differ [25-27].

Indeed, let agent k's demand be of the form $x_{k}=\theta_{k} f(p)$, where $f^{\prime}(p)<0$, then, despite the difference in the demand functions, the price elasticity of demand for different consumers at the same tariff $\mathrm{p}$ will be the same. Let us show that in this case, for any level of resource shortage, an increase in tariffs and proportional rationing will lead to the same levels of water consumption for each agent. For a given value $\beta$ we find the corresponding tariff $p_{\beta}$ as a solution to the equation

$$
F(p \beta) \sum_{k=1}^{M} \Theta_{k}=\beta X .
$$

at that

$$
X=\sum_{k=1}^{M} x_{k}(p)=f(p) \sum_{k=1}^{M} \Theta_{k}
$$

where $f\left(p_{\beta}\right)=\beta f(p)$, which leads to the desired result:

$$
x_{k}(p \beta)=\theta_{k} f(p \beta)=\beta \theta_{k} f(p)=\beta x_{k}(p) .
$$

\section{Conclusion}

In the second example, proportional quotas also turn out to be better than universal quotas, since they allow taking into account the difference in estimates of water consumption, but entail large losses compared to tariff regulation, since in the example under consideration the elasticity of demand of the two groups is different (the first group has a more elastic demand). As a result, quotas proportional to the previous consumption levels turn out to be different from effective ones, which leads to higher losses. The least effective way to regulate the deficit for any specification of demand is the policy of periodic shutdown of water supply. Consumer losses decrease if there is a possibility of water redistribution between periods; however, the calculations do not consider the costs associated with the purchase, installation and operation of this equipment, and therefore the actual losses will 
be slightly higher. Even though the policy of interruptions in the supply of water (even with water storage equipment) leads to large losses compared to other options, this method of rationing is widely used in developing countries. Apparently, the reason is that other rationing schemes, like tariff regulation, require the installation of water meters, which, as a rule, have a small proportion of the population in developing countries. In addition, these options require certain costs associated with monitoring and control, while restrictions on the water supply allow you to regulate the volume of water consumption without additional costs.

\section{References}

1. Stephan Pfister. Peter Bayer. Annette Koehler. and Stefanie Hellweg. Environmental Impacts of Water Use in Global Crop Production, Hotspots and Trade-Offs with Land Use. Environmental Science \& Technology 45 (13). 5761-5768/ DOI: 10.1021/es1041755, (2011).

2. José Galizia Tundisi. Water resources in the future: problems and solutions. 22 (63) São Paulo, (2008).

3. Animesh K. Gain .Md. Sarwar Hossain.David Benson.Giuliano Di Baldassarre.Carlo Giupponi and Nazmul Huq. Social-ecological system approaches for water resources management, International Journal of Sustainable Development \& World Ecology. 27. pp. 109124. (2020).

4. Water for a sustainable world. The United Nations World Water Development Report. p. 140. (2015).

5. Socio-ecological perspectives on water. https://www.niva.no/en/services/socio-ecologicalperspectives-on-water

6. J.M.C.K. Jayawardana. Water Resource and the Aquatic Environment: Current Issues and Options for Sustainable Management. p 135. ISBN: 978-1-63485-881-6 (2016).

7. Carr. G. D. P. Loucks. and G. Blöschl. Evaluating participation in water resource management, A review. Water Resour. Res. 48, (2012)

8. William J. Cosgrove, and Daniel P, Loucks. Water management: Current and future challenges and research directions, Water Management Research Challenges. 51. (6). pp 4823-4839. (2015).

9. $\quad$ United States Department of Agriculture. Irrigation and Water Use. (2010).

10. Falkenmark. M.J. Lundquist and C. Widstrand, Macro-scale Water Scarcity Requires Microscale Approaches, Aspects of Vulnerability in Semi-arid Development". Natural Resources Forum. 13. (4). pp. 258-267. (1989).

11. Paul Ruess. Mapping of Water Stress Indicators. CE 394K GIS in Water Resources Fall, (2015).

12. The Water Poverty Index: International comparisons. (2002)

13. Simon Damkjaer and Richard Taylor. The measurement of water scarcity: Defining a meaningful indicator, PMC. Sep; 46 (5), pp 513-531, (2017)

14. Elpiner L.I. Chupis A.V. Panasovsky Y.V. Socio-ecological issues of water use resources. Moscow, p 136. (1992).

15. Chernyaev A.M. Prokhorova N.B. Dalkov M.P. Shakhov I.S. Pool-P. Sustainable management strategy water use, RosNIIVKh. - Yekaterinburg: Publishing house "Victor". p 236. (1997)

16. Anischenko L.Ya.. Strolberg F.V.. Sukhorukov G.A. Methodology for calculating water protection measures for flow distribution, Water resources, 1. -pp. 94-101. (1982).

17. Sullivan C. Meigh J. Lawrence P. Application of the water poverty index at different scales, A cautionary tale. Water International. 31, pp 412-426, 2006)

18. Vavilin V.A. Tsitkin M.Y. Mathematical modeling and quality management of the aquatic environment. Water resources. № (50). pp. 114-132. (1977)

19. Bazarov A.K. Chertovitsky A.S. Issues of paid water use, Agrarian science. Journal of the Interstate Council for Agrarian Science and Information of the CIS countries. - Moscow. (11), pp.18-20. (2005)

20. Rational use of water resources in the basin. The Azov Sea. Mathematical Models, Moscow, Nauka. p. 360, (1981) 
21. Navruzov S.T. Modeling in water resources management. - Dushanbe: "ER-graph". p 280. (2013)

22. Jasper M. Dalhuisen. Raymond Florax. Henri de Groot and Peter Nijkamp Price and Income Elasticities of Residential Water Demand, A Meta-Analysis. Land Economics. 79. (2). pp 292308, (2015)

23. Yakubov M. S. Aidarova A. b. Models of rational water resources distribution in ULM-regions Scientific progress, Scientific and practical journal. (1) pp 15-17. Ufa, (2017)

24. Aydarova A.B. Yakubov M.S. Development of a model for the rational distribution of water resources in the Chirchik river basin. SCIENCE TIME. Society for Science and Creativity. International scientific journal. (1). Pp. 12-17. (2017)

25. Yakubov M.S. Aydarova A.B. Distributed land management in ULM regions. Problems and prospects for the development of innovative cooperation in scientific research and training system. Materials of the international conference of the scientific and practical conference. pp 333-335, Bukhara (2017) 